\title{
A teatralidade como um choque entre visualidades (e a questão da realidade em cena $)^{1}$
}

\section{Theatricality as clash between visualities (and the question about reality on the scene)}

Rejane Kasting Arruda² 


\section{Resumo}

A recusa da visualidade de um universo diegético fechado, onde 0 indivíduo encontra-se implicado em relações intersubjetivas a serem representadas, está articulada a um projeto moderno de construção de um saber sobre o sujeito contemporâneo que, por sua vez, implica proposições pós-estruturalistas. Postulase a necessidade de uma nova teoria do dramático, que se articule à problematização de um sujeito fragmentado (diferente da noção de indivíduo). Para isto, se constrói a perspectiva da fragmentação da visualidade da realidade, de maneira que seus fragmentos possam ser tomados como material no jogo da teatralidade que o dramático implicaria; o enquadramento como um conceito chave, chegando ao olhar do público como aquilo que estranha; e a noção de poético (advinda de Jakobson) como o que faz vacilar a referência.

Palavras-chave: Teatro pós-dramático; teatro dramático; teatralidade; realismo

\section{Abstract}

The refusal of a closed diagetc universe's visuality, where the individual is implicated in intersubjective relations to be represented, is articulated to a modern building of knowledge on the contemporary subject which, in turn, implies poststructuralist propositions. It is postulated the need for a new theory about the dramatic, which could be articulated to the problematization of a fragmented subject (other than the notion of the individual). For this, it is built the perspective of the visual fragmentation of reality, so that fragments may be used as materials in the game of theatricality which the dramatic implies; the framing as a key concept, coming to the audience's eye as what is estranged; and the notion of poetic (arising from Jakobson) as which makes the reference to falter.

Keywords: Posdramatic theatre; dramatic theatre; theatricality; realism

ISSN: 1414.5731

\footnotetext{
${ }^{1}$ Este trabalho contou com apoio da Fundação de Amparo à Pesquisa no Estado de São Paulo.

2 Universidade Vila Velha (UVV). Profa Dra. Vila Velha (ES).

rejane.arruda@uvv.br
} 
No desenrolar da cena teatral no século XX nos deparamos com uma clássica oposição. Por um lado, temos uma plasticidade estranhada. Uma plasticidade que se encontra, em projetos estéticos diversos, sustentada por materiais diferentes: seja uma forte presença da abstração, uma poética da precisão, o extracotidiano, experimentos com a sonoridade ou uma poética da disjunção quando a palavra evoca algo que não se articula ao que o corpo evoca (como muitas vezes faz Bob Wilson, por exemplo). De uma forma ou outra, são projetos que articulam um discurso antirrealista; contra a visualidade de uma suposta realidade que estaria representada (ou mimetizada quando circunscrita a ações por sua vez evocadas por um texto dramático), apesar de implicar operações de extração e montagem.

Queremos trabalhar uma perspectiva da fragmentação dessa visualidade, a fim de tomá-la como material no jogo do que seria teatral. Por exemplo, o que se chamou de "ressignificação de um objeto": um procedimento comum, utilizado para a criação de uma poética cênica. O seu efeito estaria na diferença entre a visualidade de um contexto e de outro; entre a visualidade do contexto onde o objeto estava inscrito e a visualidade das relações que a cena evoca, de maneira a inscrevê-lo em um lugar que não é o dele. Uma vassoura quando enquadrada na visualidade de certa relação é um homem. Poderíamos dizer que a visualidade da relação com o homem enquadra o objeto vassoura. O objeto é extraído da visualidade de uma realidade e posto na visualidade de uma relação, que o enquadra como outra coisa, causando um efeito de teatralidade. Esta é a hipótese: a realidade como superfície (visual) da qual se extrai pedaços. Objetos, fatos, imagens são passíveis de extração e enquadramento ao se inscrever na visualidade da cena, que por sua vez está bordeada por um olhar e constituída por ele.

Efeitos de teatralidade poderiam advir também da abstração de um desenho que oferece ao corpo o estatuto de extracotidiano, quando em choque com o olhar do espectador, que tenta enquadrá-lo na visualidade de ações. Por um instante, se consegue produzir um enquadramento para o abstrato, mas este se dilui; não se sustenta por muito tempo nos desdobramentos do eixo horizontal da cena. Vemos isto nos espetáculos de Pina Bausch, por exemplo. Um flash, um fragmento da visualidade de uma situação que se dilui. Seriam as tentativas de enquadre pelo espectador que provocam o efeito de teatralidade. Isto na medida em que o encaixe é sempre inapropriado, pois a plasticidade corporal está para além da ação com a qual o espectador tenta enquadrá-la. Visualidades são relativamente autônomas e podem ser recortadas, para se por, lado a lado, por contraste ou diluição, gerando efeitos de teatralidade. Relações inscritas na visualidade de uma realidade só se sustentariam enquanto desmembradas, para se unir a outras no olhar. De maneira que uma realidade sem fissuras, inteiriça e tomada enquanto fato a ser representado não seria possível.

Mas os Naturalistas queriam o teatro como uma prova, como garantia de uma verdade supostamente científica e reproduzível sobre a realidade. Apesar disto, não escaparam dos efeitos da teatralidade quando, por exemplo, um Antoine coloca carne na cena. E no trabalho do ator? Na atuação realista? Poderíamos dizer também que, apesar de não se investir numa poética do desenho, da precisão ou da abstração, implicaria o choque? A visualidade de uma atuação realista implica certos significantes, como: imprecisão, intimidade, cotidianidade (um corpo ordinário, apesar dos traços particulares). Seria este 
corpo, que não imprime a plasticidade de um tratamento extracotidiano capaz de evocar efeitos de teatralidade quando participa de um jogo de enquadramento?

No cinema, muitas vezes, a atuação realista depende de uma diluição da visualidade do ato de representar. $O$ "como se fosse" (realidade) é determinante e o ator não pode participar do jogo como nota dissonante. Ele precisa se misturar à visualidade da diegese. Qualquer técnica é disfarçada, qualquer visualidade do ato de representar é mal visto. O que muitas vezes se estranha é o enquadramento cinematográfico, que pode denunciar a plasticidade de um olhar da câmera (e também do espectador). Já o ator é objeto banalizado no discurso fílmico. Como se partíssemos de cores pálidas para pouco a pouco despontar as fissuras, brechas de desarmonia (um estranhamento desponta no horizonte quando tudo parece normal).

Acredito em uma possível retomada da inscrição de uma cotidianidade do corpo na cena teatral, de maneira que se choque com as imagens evocadas por palavras de um texto dramático, implicando a visualidade do olhar (do espectador e do próprio ator) para o que não se adéqua; o que escapa do enquadramento oferecido pelas ações; um diferente, que o ator encena e desponta quando algo impregnado na tessitura corporal ganha luz: a luz do olhar que o observa (e que se choca).

$\mathrm{Na}$ atuação realista o "como se fosse" não estaria bem próximo de fazer vacilar uma realidade quando se trata de ocupar o seu lugar? Substituída no dispositivo, tratada pela cena que a coloca em perspectiva. Não se trata da deformação ou da violência, da abstração ou do ritual, do objeto enquadrado como outra coisa; não se trata do extracotidiano de Meyherold, Brecht, Appia, Grotowski, Simbolistas, Barba ou Decroux. Conta-se com a visualidade enigmática de um pensamento que aparece como estranho quando inscrito em um corpo que se dilui na visualidade da diegese.

No cinema, Bazin postulou que uma "verdade" poderia ser revelada através do plano sequencia. As ações deveriam ser capturadas no tempo real para que uma espécie de brilho aparecesse: algo impossível de se ver a olho nu, mas que a película imprime. Segundo ele, não deveria haver montagem para não falsear aquele instante. No entanto, a montagem se estabelece quando se trata do que se pode e do que não se pode ver, já que houve a extração de um pedaço. A continuidade do olhar é limitada pelas bordas de um enquadramento cinematográfico. Esse brilho que Bazin queria não seria o brilho do olhar do espectador cuja visualidade é de repente capturada pelo recorte cinematográfico? Tal como se daria na cena teatral: o enquadramento do olhar se torna evidente.

O Naturalismo no teatro buscava revelar uma verdade sobre a vida: mostrá-la sem falsear. As ferramentas clássicas pareciam-lhe falsas, pois a unidade de tempo e ação não seria própria da realidade. O compromisso estava no registro, no documento. No entanto, forja-se uma espécie de estética da crueza - sem aquela frontalidade dos gestos, grandiloquentes, com os quais os atores evidenciavam a visualidade da sua relação com a plateia. Busca-se diluir a presença do espectador, que passa a olhar através de uma quarta parede transparente e se torna voyeur lou cientista). O realismo esconde a visualidade do olhar do espectador, que não pode interferir para que a verdade se revele. Muito próximo ao que Bazin propõe na sua apologia ao plano sequencia.

A intenção do projeto naturalista de trazer a realidade à cena, por um lado implica o choque entre pedaços (como a carne) diante de uma recomposição. Por 
outro, implica o choque entre o que se esconde e o que é mostrado. Uma verdade das relações sociais passa a ser olhada e a suposta aparência (ou a superficialidade que estaria ofuscando essa verdade). Trata-se de colocá-la fora: fora do olhar. A noção de desvelamento implica choque entre visualidades. A visualidade da aparência ofusca e o que é revelado e nada mais é senão outra imagem. Um teatro realista, que implicaria a mimese, torna-se uma espécie de signo de um paradigma que desmoronou: a inteireza da realidade.

Assim, no decorrer do século XX, o discurso antirrealista validou diferentes projetos estéticos. $\mathrm{E}$ a teoria do pós-dramático, um dos pilares da cena contemporânea, veio a contribuir para a estruturação de um campo conceitual para uma poética cênica que se recusa à representação do suposto universo fechado oferecido por um texto dramático. No entanto, podemos abrir a perspectiva de um caráter fragmentado desse suposto universo inteiriço. Não se trata somente de substituir os termos: representação por visualidade. Mas de inscrever o dramático em outro discurso.

No século XX, a fragmentação, a ruptura, o estranhamento, foram definitivos para a oposição à representação desse suposto universo fechado (que um texto dramático evocaria, com personagens, diálogos e situação). Seria preciso criar outros discursos que sustentem a fragmentação como princípio também do dramático? Como estrutural para os efeitos da teatralidade independente da modalidade do jogo? Evocar uma visualidade familiar (de uma realidade) não seria explorar o estranhamento do olhar sobre ela? Não se poderia explorar o choque da visualidade deste olhar que constrói um enquadramento e gera efeitos por implicar a inadequação? Não se produz algo de estranho, advindo da inadequação de uma escrita cênica à visualidade evocada pelas palavras do texto? Como se o estranhamento fosse destino, fosse estrutura, qualidade inerente da poética cênica?

O discurso contra o figurativo, a representação ou a mimese, ao se instalar no senso comum, torna-se passível de desconfiança. Quando a palavra de ordem passa a ser não-drama, não-mimese, não-representação, não-sentido, os termos geram consequência. Nós, que estamos próximos à pesquisa prática na academia, talvez possamos perceber o quanto a apologia a certa imanência do objeto, muitas vezes, nos impede de encenar (a apologia ao objeto que não representa, não significa, não determina o olhar e seria sensorial, aberto).

Mas, ao contrário, poderia haver no dramático, mesmo com o sentido da ação implicado, uma singularidade do enquadre oferecido pelo espectador? Não seria este olhar que oferece à cena o seu estatuto? Mesmo que engendre imagens articulando ações com a visualidade da diegese? Visualidade que implica o fragmento, pois, mais que circunscrita a uma série de associações (que evocam o que se convencionou chamar universo fechado), a imagem da ação é apenas uma das coisas que o espectador olha. Outras visualidades implicam uma rede de fragmentos dispersos que ele junta.

Quando o pós-dramático defende que não se pode juntar, que a disjunção é a lei, trata-se de produzir poética. No entanto, isso pode ser tomado como uma estrutura da cena e não como um fundamento para a posição anti-dramática. Reconhecemos que a operação que advém do pós-dramático não é fora do sentido: há enquadramento. Ao mesmo tempo em que, no dramático, o enquadramento pode se romper (conforme o que o discurso cênico evoca de novo e o que o espectador pro- 
duz). Também pode se romper quando se choca com a poética da cena, que conta com um corpo. O choque entre o que estaria fora das bordas desse corpo e o que é evocado como dentro (o pensamento) implica efeito de teatralidade. Não basta inscrever a cotidianidade; é preciso inscrever o pensamento, que se torna enigmático e passa por sucessivas tentativas de enquadre por parte do espectador.

A teoria do pós-dramático trouxe categorias para uma modalidade de análise que se concentrava na teoria da significação e em uma abordagem semiótica. Agora, trazendo para o debate as categorias da visualidade e enquadramento, não seria o caso de percebermos que uma representação só existe em função de uma bateria de significantes específica, e que engendra associações particulares para cada sujeito a partir do choque com visualidades complexas e dissonantes?

Em certo momento, em palestra de Feral na Universidade de São Paulo, escutei que o conceito de arte está morto. Seria o caso de utilizar-se da noção de poética? Para Jakobson o discurso poético é aquele que faz vacilar a referência: "A supremacia da função poética sobre a função referencial não oblitera a referência, mas torna-a ambígua" (Jakobson, 2007, p. 100). Haveria uma poética que, implicando a visualidade da realidade a faz vacilar? Talvez a cotidianidade do corpo articulada à visualidade do pensamento (implicada no projeto de atuação realista) somente ao fazer vacilar aquilo que representa (um indivíduo) alcançaria o estatuto de poético.

Nas seguidas críticas ao realismo encontramos um alvo: o ator, que ofuscaria as outras visualidades graças a sua compulsão pelo exagero. $O$ pós-dramático o eximiu dessa culpa quando enquadrou o seu excesso como plasticidade da cena. Mas, na atuação realista, a exacerbação da plasticidade corporal pode ofuscar outras visualidades: da ação e do pensamento. Seria melhor ser simples, em um corpo cotidiano enquadrado por ações que palavras evocam. Esta tríade "pensamento, cotidiano e ação" seria como que um arranjo para certo tipo de atuação, articulando significantes como comum e humano. Do choque da visualidade do olhar sobre o corpo ordinário, sujo, impreciso e impregnado de pessoalidade do ator, se extrai um resto (que produz poética por não encontrar lugar, fazendo vacilar "a referência", como diz Jakobson)? Referência que não é mais que certa visualidade?

Mas, será que para além dos objetos estéticos, não estaria implicada uma ética da edificação de um saber sobre o sujeito? Categorias como fragmentação, diferença, deslizamento, descentramento, presença. Como se a cena pós-dramática servisse à teoria do sujeito contemporâneo. Será que não seria preciso construir o discurso do dramático que articule as questões do sujeito? Fundamentar a cena como uma reverberação de um saber.

Segundo Lacan, se enlaçar a um discurso é um ato. Um ato no sentido de que não é mais possível voltar atrás. Talvez o enlaçamento no discurso contemporâneo implique que não se possa mais voltar ao discurso da representação do qual o dramático foi feito signo. Não seria a fidelização ao sujeito contemporâneo que inscreve a poética pós-dramática em uma perspectiva histórico-desenvolvimentista - como se estivesse à frente de outras?

Trata-se aqui de implicar a obra como racionalidade. Ela porta uma razão. Não de ser, justificada quando se articula à edificação discursiva. Mas ela porta um saber (ou um saber que não se sabe, como diz Lacan). Por que a poética dramática foi destituída do saber sobre o sujeito? Porque o sujeito não é um indivíduo inteiro dedicado a relações intersubjetivas. É como se, ao colocar em questão o indivíduo, ela se eximisse 
do propósito de falar de um sujeito: não inteiro, fragmentado, dividido, descentrado, estranhado, sem lugar, que apareceria na tessitura pós-dramática (na própria forma da sua tessitura). Qual seria a ética do dramático? Talvez, fazer vacilar. E fazer vacilar justamente a visualidade do indivíduo, na medida em que isto alucina, que é pura visualidade - e se choca com o olhar que a enquadra, colocando-a, também, em questão.

A ética do pós-dramático, que implica predominantemente uma recusa de um universo fechado (onde os indivíduos estão implicados em relações intersubjetivas a serem representadas) - e que se solidifica em oposição ao dramático - ironicamente deslocou a relação intersubjetiva o espectador, trazendo o conflito para o eixo extraficcional: chocar o espectador; colocá-lo em questão, colocar a visualidade de suas identificações em questão, mostrar-lhe o processo de construção da obra, etc.

A performatividade como oposta à representação, na qual o drama estaria implicado: esta é a tese consolidada contemporaneamente. Não cabe aqui realizar uma digressão para mapear suas origens e problematizá-la. Basta testemunhar que novos pesquisadores a assumem como discurso. Ou seja, é uma tese que vem sendo desdobrada nas pesquisas contemporâneas.

\footnotetext{
O teatro tradicional trabalha com a ideia de manutenção de um universo fictício fechado. É um tipo de representação cênica com uma realidade emoldurada, encerrada em leis próprias e com uma lógica interna entre os elementos. Esse enquadramento fictício ignora a ideia de que o teatro é um "processo in actu". O teatro tem como especificidade o fato de que é a um só tempo processo material e signo, prática real e significante. Os produtos materiais da cultura são usados como signos estéticos no teatro, e isto é o que torna possível um "para além da interpretação" e a "estética da irrupção do real" A partir dos anos 70, diversas manifestações da arte teatral empreenderam uma revolução na "representação dramática imitativa" e propuseram um teatro para além dos limites do significado, da cópia e do ordenamento centrado no logus. O novo teatro não é mais visto como lugar do simulacro, da ilustração da ação, da duplicação de outra realidade; nele, "o real passa a ter o mesmo valor do fictício" (Bond, 2010, p. 01).
}

Tal como se encontra inscrito nesse discurso (de acordo com a tese de que representa um universo fechado através da mimese), o dramático é um desvalor. Situado como superado, ele deixa de ser problematizado, ficando a encargo de um mercado que o banaliza, quando apenas repete padrões (sem a reflexão que determina a montagem teatral como uma práxis). O que, para nós, apenas reafirma a necessidade de uma nova teoria do drama, a fim de articulá-lo a um discurso que o apresente como um campo de debate das questões do sujeito contemporâneo (como acontece com o pós-dramático), o retirando do âmbito das significações e o inserindo como uma das modalidades possíveis do choque entre visualidades.

Acredito que certa racionalidade da arte porta implicações do saber sobre o sujeito; e que esta poética que nos antecede (a cênica) articula esse saber e implica, tanto no artista quanto no espectador, a pulsão do saber. Uma pulsão que, sendo pulsão é corpo. Acredito que o estranhamento da alucinação da visualidade de um cotidiano mimético (evocada com o drama intersubjetivo), deixe escapar a evidência do olhar que a enquadra - apontando para as bordas de um quadro, na medida em que, para além dele, tem apenas o vazio. Vazio que a imagem tampona e que o jogo poético faz vacilar quando trabalha na chave do "como se" (fosse real).

A teatralidade evidencia que não é. E no realismo, esta deve advir de cada imagem que se evoca e choca com a outra, por fim rompendo, perfurando as bordas de 
um enquadre que insiste em ser báscula - em balizar certa estabilidade (certas determinações com as quais se está acostumado, mas que não se sustentam, por estarem fora do campo da poética). Talvez, ao invés de dividir o campo teatral entre dramático e pós-dramático, poderíamos dividi-lo entre o poético e aquele que não conseguiu esse estatuto. Mas isto não seria eximir-se de uma perspectiva histórica da encenação? Afinal, o que é poético em cada momento histórico?

De qualquer maneira, cada momento implica um discurso para validar o que é poético. O pós-dramático implica um campo no discurso. E não é mais possível dele se afastar. Parece que ele dá a voz a uma espécie de sem lugar do sujeito, quando este é especularizado como fragmentação. $O$ discurso da multiplicidade e fragmentação valida uma não articulação da qual o efeito de sujeito depende. De forma a tentar fugir da inteireza das relações de sentido. No entanto, se cai na inteireza de relações imaginárias nas quais o espectador (este que se pretende provocar, chocar) faz parte: um indivíduo em risco. Leia-se "drama", pois, acaso não se deixa transparecer a posição dramática em que o espectador se encontra?

\footnotetext{
Cabe ao teatro o papel de, por meio de uma estética do risco, lidar com afetos extremos, que sempre incluem a possibilidade da dolorosa quebra do tabu. Essa quebra ocorre quando os espectadores são expostos ao problema de reagir àquilo que se passa diante deles de modo que não mais exista a distância segura que parece garantir a diferença estética entre a sala e o palco. Justamente essa realidade do teatro, o fato que ele pode brincar com tais limites, o predestina a atos e ações nos quais não se formula uma realidade "ética" ou mesmo uma tese ética; antes, surge uma situação na qual o espectador é confrontado com o medo abissal, com a vergonha e também com a irrupção da agressividade (Lehmann, 1999, p. 427).
}

Talvez exista também no dramático um caminho de fazer vacilar aquele que olha: potencializando choques entre as visualidades que este produz para evidenciar o que há de fragmento na suposta unidade do mundo representado. Afinal, não se pode tomar o funcionamento da linguagem (a fragmentação e os deslizamentos do significante) desarticulando-a da unicidade de uma imagem que vela o vazio que por trás se insinua, seja no campo do "como se (o ator fosse o personagem)" ou no drama do "é" (o espectador) do pós-dramático. Como se com a sucessão de choques, em certo instante, quase sem querer, a imagem se quebrasse e revelasse que por trás há um espaço de ausência.

\section{Referências}

BOND, Fernanda. 2010. O Ator autor: a questão da autoria nas formas teatrais contemporâneas. VI Congresso de Pesquisa e Pós-graduação. São Paulo: ABRACE, 2010. Disponível: http://portalabrace.org/vicongresso/processos/ Fernanda\%20 Bond\%20 -\%200\%20Ator\%20autor.pdf. Acesso em: 01 jun. 2014.

JAKOBSON, R. Lingüística e Comunicação. São Paulo: Cultrix, 2007.

LEHMANN, H. Teatro Pós-Dramático. São Paulo: Cosac Naify, 1999.

Recebido em 01/06/2014

Aprovado em 23/06/2014 